\title{
cAMP Elevation Down-Regulates $\beta 3$ Integrin and Focal Adhesion Kinase and Inhibits Leptin-Induced Migration of MDA-MB-231 Breast Cancer Cells
}

\author{
Annamaria Spina, Francesca Di Maiolo, Antonietta Esposito, Luigi Sapio, \\ Emilio Chiosi, Luca Sorvillo, and Silvio Naviglio
}

\begin{abstract}
Breast cancer is one of the most common malignancies and a major cause of cancer death among women worldwide. The high mortality rate associated with breast cancer is mainly due to a propensity of the tumor to metastasize, even if small or undetectable. Given the relevant role of leptin in breast cancer growth and metastasis, novel strategies to counteract biological effects of this obesity-linked cytokine are warranted. Recently, we demonstrated that in MDA-MB-231 breast cancer cells, intracellular cAMP elevation completely abrogates both ERK1/2 and STAT3 phosphorylation in response to leptin. Very surprisingly, this provided evidence that when cAMP levels are increased, leptin drives cells towards apoptosis associated with a marked decrease of Bcl2 protein levels and accompanied by down-regulation of protein kinase A (PKA). The aim of the current study was to investigate the role of cAMP in leptin-associated motility of breast cancer cells. Here we show that cAMP elevation completely prevents leptin-induced migration of MDA-MB-231 breast cancer cells. Interestingly, the inhibition by cAMPelevating agents of leptin-mediated cell migration is accompanied by a strong decrease of $\beta 3$ integrin subunit and focal adhesion kinase (FAK) protein levels. Analysis of the underlying cAMP-dependent molecular mechanisms revealed that PKA blockers partly counteract the inhibition of leptin-induced migration and completely prevent the antiproliferative action by cAMP elevation. Moreover, a cAMP analogue that specifically activates Epac and not PKA has an inhibitory effect on leptin-induced cell migration as well. The present study confirms initial evidence for the efficacy of cAMP elevation against oncogenic effects of leptin, identifies $\beta 3$ integrin subunit and FAK as proteins strongly down-regulated by cAMP elevation, and suggests that both cAMP/PKA- and cAMP/Epac-dependent pathways are involved in inhibition of leptin-induced migration of MDA-MB-231 breast cancer cells. The potential clinical significance and therapeutic applications of our data are discussed.
\end{abstract}

Key words: breast cancer cells; cAMP; leptin; migration; novel anticancer therapies

\section{Introduction}

B REAST CANCER IS ONE OF the most common malignancies and a major cause of cancer death among women worldwide, with an estimated 1 million women diagnosed annually. According to the American Cancer Society, nearly 230,000 new cases and 40,000 deaths occurred in the United States in 2011. ${ }^{1}$

Early and localized breast cancer can be successfully treated by surgery alone. However, there is a high mortality rate associated with breast cancer that is mainly due to a propensity of the tumor to metastasize even when the primary tumor is small or undetectable. ${ }^{2}$

Metastasis is a complex and multistage process in which secondary tumors form at distant sites. ${ }^{3}$ Typically, the devel- opment of metastasis involves several steps including migration and invasion of tumor cells within the primary site; intravasation into blood, lymphatic vessels, or both; survival and dissemination in the circulation; adherence to vascular endothelial cells at secondary sites; and extravasation, colonization, and population to form micro- to macro-metastatic foci. The migratory ability of the cancer cells is important for many of these steps, and therefore is relevantly correlated with tumor metastasis. ${ }^{4}$ Currently, new effective therapies are needed for the treatment of metastatic breast cancer. ${ }^{5,6}$

Leptin is the peptide hormone product of the obesity gene. ${ }^{7}$ Leptin is a well-known factor involved in the regulation of body weight and body composition and is an important mediator of obesity. ${ }^{8}$ The circulating leptin acts as a regulator of food intake via hypothalamic-mediated effects. ${ }^{9}$ Since the circulating

Department of Biochemistry and Biophysics, Second University of Naples, Medical School, Naples, Italy. 
levels of leptin are elevated in obese individuals, and obesity has been shown to increase breast cancer risk in women, several studies have addressed the role of leptin in breast cancer. ${ }^{10}$

Remarkably, both leptin and its receptors are overexpressed in breast cancer, especially in high-grade tumors, including triple-negative cancers, and leptin acts as a mitogen/ survival factor in breast cancer cells. ${ }^{11-16}$ In addition, leptin has been characterized as a potent agent inducing breast cancer cell migration and invasion. ${ }^{17,18}$

Importantly, given the relevant role of leptin in breast cancer growth and metastasis, the leptin system has emerged as a new and promising therapeutic target for breast cancer. ${ }^{19}$ So far, novel strategies to counteract biological effects of this obesity-linked cytokine are warranted. Recently, we demonstrated that in MDA-MB-231 breast cancer cells, intracellular cAMP elevation completely abrogates both ERK1/2 and STAT3 phosphorylation in response to leptin. Very surprisingly, this provided evidence that when cAMP levels are increased, leptin drives cells towards apoptosis associated with a marked decrease of $\mathrm{Bcl} 2$ protein levels and accompanied by down-regulation of protein kinase A (PKA). ${ }^{20,21}$

Despite their potent antiproliferative effects in many cancer cells, including breast cancer cells, agents that increase intracellular cAMP levels are not recommended to be used as anticancer drugs because of their high cytotoxicity. ${ }^{22}$

Surprisingly, we found a positive pharmacological interaction between leptin and cAMP-elevating compounds that allowed reducing the effective doses of the compounds in vitro, thus potentially decreasing their undesirable side effects in vivo. ${ }^{20,23}$

The present study was designed to investigate the role of cAMP in leptin-associated motility of breast cancer cells. Intriguingly, we found that cAMP elevation, in addition to inhibiting proliferation, also inhibited migration of highly invasive MDA-MB-231 breast cancer cells in response to leptin. Importantly, we also report that expression of some relevant proteins involved in breast cancer metastasis are strongly inhibited by cAMP elevation and that both cAMP/ PKA- and cAMP/Epac-dependent pathways are involved in inhibition of leptin-induced migration of MDA-MB-231 cells. The potential clinical significance and therapeutic applications of our data are also discussed.

\section{Materials and Methods}

\section{Materials}

All cell culture materials were from Gibco-Life Technologies (Gaithersburg, MD). Human recombinant leptin, 8-BrcAMP, cAMP analogue 8-pCPT-2'-O-Me-cAMP, forskolin, 3-isobutyl-1-methylxanthine (IBMX), KT5720, and H89 (PKA inhibitors) were purchased from Sigma (SigmaAldrich, St. Louis, MO). Anti-tubulin antibodies were obtained from Oncogene-Calbiochem (La Jolla, CA). Anti-pERK, anti-focal adhesion kinase (anti-FAK), and anti-p-FAK antibodies were obtained from Cell Signaling Technology (Danvers, MA). All other antibodies were obtained from Santa Cruz Biotechnology (San Diego, CA).

\section{Cell culture and treatments}

The MDA-MB-231 human breast cancer cell line was obtained from the American Type Culture Collection (Rock- ville, MD). MDA-MB-231 cells were grown in Dulbecco's modified Eagle's medium (DMEM) supplemented with $2 \mathrm{mM}$ glutamine, $100 \mathrm{U} / \mathrm{mL}$ penicillin, $100 \mathrm{mg} / \mathrm{mL}$ streptomycin, and $10 \%$ fetal bovine serum (FBS) and cultured at $37^{\circ} \mathrm{C}$ in a $5 \% \mathrm{CO}_{2}$ humidified atmosphere. Typically, cells were split $\left(8 \times 10^{5} / 10\right.$-cm plate $)$ and grown in $10 \%$ serumcontaining medium. After $24 \mathrm{~h}$, the medium was removed, cells were washed with phosphate-buffered saline (PBS) and cultured in low-serum $(0.1 \%)$ fresh medium. After $36 \mathrm{~h}$ of serum starvation, cells were washed with PBS. Treated cells were exposed to cAMP-elevating agents and/or leptin in $0.1 \%$ serum-containing medium for the times indicated in Results; control cells were not treated. Leptin was prepared in $\mathrm{HCl} / \mathrm{NaOH}$ solution according to preparation instructions by Sigma; 8-Br-cAMP was prepared in water; and forskolin and IBMX were prepared as stock solutions in DMSO and ethanol, respectively. Dilutions were made such that the final concentration of solvent(s) was kept below $0.1 \%$, and control cells were treated with an equivalent volume of solvents. $^{20,21}$

\section{In vitro wound-healing cell migration assay}

Cell migration assays were performed as described previously. ${ }^{24}$ Typically, cells were split $\left(5 \times 10^{5}\right.$ per $6-\mathrm{cm}$ plate $)$ and grown in $10 \%$ serum-containing medium. After $24 \mathrm{~h}$, the medium was removed, and cells were washed with PBS and cultured in $10 \%$ serum fresh medium.

Approximately 36-48 h later, when cells were 95\%-100\% confluent, the medium was removed, and cells were washed with PBS and cultured in low-serum $(0.1 \%)$ fresh medium. After $24 \mathrm{~h}$ of serum starvation, a gap was introduced into the monolayer cells by dragging a pipette tip across the cell surface. Medium and nonadherent cells were removed; cells were washed twice with PBS; and new $0.1 \%$ serum medium without (control) or with leptin, forskolin (or other cAMP elevating agents), or leptin plus forskolin was added. Cells were permitted to migrate into the area of clearing for up to $48 \mathrm{~h}$. Wound closure was monitored by visual examination under microscope.

The phase contrast images of the wounds were recorded after $0,10,24$, and $48 \mathrm{~h}$, at the identical location of the initial image, and the wound closure was evaluated by measuring the width of the remaining wound. All experiments were performed at least three times.

\section{Transwell migration assay}

Cell migration was also studied by seeding cells $\left(1 \times 10^{5}\right)$ into polycarbonate membrane inserts $(8-\mathrm{mm}$ pore size) in 24-transwell cell culture dishes, and allowing them to migrate through the pores.

Cells were permitted to migrate for $10 \mathrm{~h}$. After the incubation, stationary cells were removed from the upper surface of the membranes. The cells that had migrated to the lower surface were fixed and stained with $0.1 \%$ crystal violet. The number of stained cells was counted under an ocular microscope.

\section{Cell proliferation assay}

Cells were seeded in 96-multiwell plates at a density of $8 \times 10^{3}$ cells/well and managed as described in Cell culture 
and treatments. Viable cells were determined by the 3[4,5-dimethylthiazol-2-yl]-2,5-diphenyltetrazolium bromide (MTT) assay, as previously described. ${ }^{20,21}$ Briefly, cells were treated with cAMP-elevating agents and/or leptin for up to $72 \mathrm{~h}$ (see figure legends). Before cells were harvested, $100 \mu \mathrm{L}$ of MTT solution $(5 \mathrm{mg} / \mathrm{mL}$ ) was added to each well and incubated at $37^{\circ} \mathrm{C}$ for $3 \mathrm{~h}$, then the formazan product was solubilized by the addition of $100 \mu \mathrm{L} 0.04 \mathrm{~N} \mathrm{HCl}$ isopropanol. The optical density of each sample was determined by measuring the absorbance at $570 \mathrm{~nm}$ versus $650 \mathrm{~nm}$ using an enzymelinked immunosorbent assay reader (Molecular Device, Sunnyvale, CA). Cell proliferation assays were performed at least four times (in replicates of six wells for each data point in each experiment). Data are presented as means \pm standard deviation for a representative experiment.

\section{Preparation of cell lysates}

Cell extracts were prepared as follows. Briefly, 3-5 volumes of RIPA buffer (PBS, 1\% NP-40, 0.5\% sodium deoxycholate, $0.1 \%$ SDS) containing $10 \mu \mathrm{g} / \mathrm{mL}$ aprotinin, leupeptin, and $1 \mathrm{mM}$ phenylmethylsulfonyl fluoride were added to recovered cells. After incubation on ice for $1 \mathrm{~h}$, samples were centrifuged at $18,000 \mathrm{~g}$ in an Eppendorf microcentrifuge for $15 \mathrm{~min}$ at $4^{\circ} \mathrm{C}$, and the supernatant (SDS total extract) was recovered. Some aliquots were taken for protein quantification according to the Bradford method; others were diluted in $4 \times$ Laemmli buffer, boiled, and stored as samples for immunoblotting analysis. ${ }^{25}$

\section{Immunodetection of proteins}

Typically, we employed $20-40 \mu \mathrm{g}$ of total extracts for immunoblotting. Proteins from cell preparations were separated by SDS-PAGE and transferred onto nitrocellulose sheets (Schleicher \& Schuell, Dassel, Germany) by a Mini Trans-Blot apparatus BioRad (Hercules, CA). II Goat anti-rabbit or antimouse antibodies, conjugated with horseradish peroxidase (BioRad), were used as a detection system (ECL) according to the manufacturer's instructions Amersham Biosciences (UK). ${ }^{26}$

\section{Statistical analysis}

Most of experiments were performed at least three times with replicate samples, except where otherwise indicated. Data are plotted as mean \pm SD (standard deviation). The means were compared using analysis of variance (ANOVA) plus Bonferroni's $t$-test, and $p$ values of less than 0.05 were considered significant. National Institutes of Health $(\mathrm{NIH})$ Image J 1.42Q (NIH, Bethesda, MD) software was used for densitometric analysis.

\section{Results}

\section{cAMP elevation inhibits leptin-induced migration of MDA-MB-231 breast cancer cells}

Recently, we showed that in MDA-MB-231 breast cancer cells, intracellular cAMP elevation completely abrogates both ERK1/2 and STAT3 activation in response to leptin. Very surprisingly, this provided evidence that when cAMP levels are increased, leptin drives cells towards apoptosis. ${ }^{20,21}$ Because ERK1/2 and STAT3 activation has been described to also be involved in migration of MDA-MB-231 cells, we pos- tulated that the leptin-induced migration of MDA-MB-231 cells may be antagonized by cAMP elevation. ${ }^{27,28}$ To test this hypothesis, MDA-MB-231 cells were treated with leptin, forskolin (a potent stimulator of adenylate cyclase cAMP biosynthetic activity), or leptin plus forskolin for up to $48 \mathrm{~h}$; control cells were untreated. The migration rate of the treated and untreated cells was measured by wound-healing assay and by transwell migration assay (Fig. 1). In the qualitative in vitro wound-healing assay (Fig. 1A), cells were grown to confluence. A wound was made in the middle of the culture plate with a pipette tip. Control cells covered the "wound" after $24-48 \mathrm{~h}$. As expected, leptin increased cell migration, and in the culture plate treated with leptin, a large part of the "wound" was already covered by cells after 10-24 hours. According to previous data regarding the antimigratory effects of forskolin in breast cancer cells, $1 \mu \mathrm{M}$ forskolin (a low dose) impressively inhibited both basal and, importantly, leptin-induced cell migration. ${ }^{29}$ Similar results were obtained with the other cAMP-elevating agents, such as phosphodiasterases inhibitor, IBMX, and cAMP analogue, 8-BrcAMP (data not shown), suggesting that cAMP elevation overcomes the strong promigratory potential by leptin on breast cancer cells. These results were confirmed with the quantitative transwell migration assay (Fig. 1B).

We do know that leptin and CAMP-elevating agents have positive and negative effects on proliferation of MDA-MB231 cells, respectively.

To exclude possible cell proliferation effects in the calculation of the number of cells that migrated, MTT assays were performed after 10 and $24 \mathrm{~h}$ of treatment without (control) or with leptin, forskolin, and leptin plus forskolin. Figure $1 \mathrm{C}$ shows that after $10 \mathrm{~h}$ cell proliferation was not yet affected by treatments, whereas cell migration was significantly affected (Fig. 1A,B).

\section{cAMP elevation down-regulates $\beta 3$ integrin and FAK}

Integrins, which regulate cell-extracellular matrix adhesions, are known to play an important role in regulating the malignant phenotype and growth of cancer cells, including breast cancer cells. ${ }^{30}$

FAK is a cytoplasmic tyrosine kinase that colocalizes with integrins in focal adhesions. The binding of extracellular matrix ligands to integrins triggers autophosphorylation at Tyr-397 and activation of FAK. FAK serves a scaffolding function for protein-protein interactions, phosphorylates multiple substrates, and regulates cross-talk between integrin and growth factor signaling to regulate cell proliferation, survival, and migration. It has been suggested that FAK may play a significant role in tumor formation and metastasis, including in breast cancer. ${ }^{31,32}$

To investigate a possible involvement of integrins and FAK in inhibitory effect of cAMP elevation on leptin-induced migration of MDA-MB-231 cells, the expression of some integrin subunits and of FAK was examined (Fig. 2). To do this, MDAMB-231 cells were left untreated or treated with leptin, forskolin, or leptin plus forskolin for $24 \mathrm{~h}$ (Fig. 2A). Then, cells were collected by scraping, total cell extracts in SDS-containing buffer were prepared, and protein levels of some integrin subunits and FAK (along with its phosphorylation status) were monitored by Western blotting analysis. Interestingly, we found that $\beta 3$ integrin subunit was strongly decreased upon 

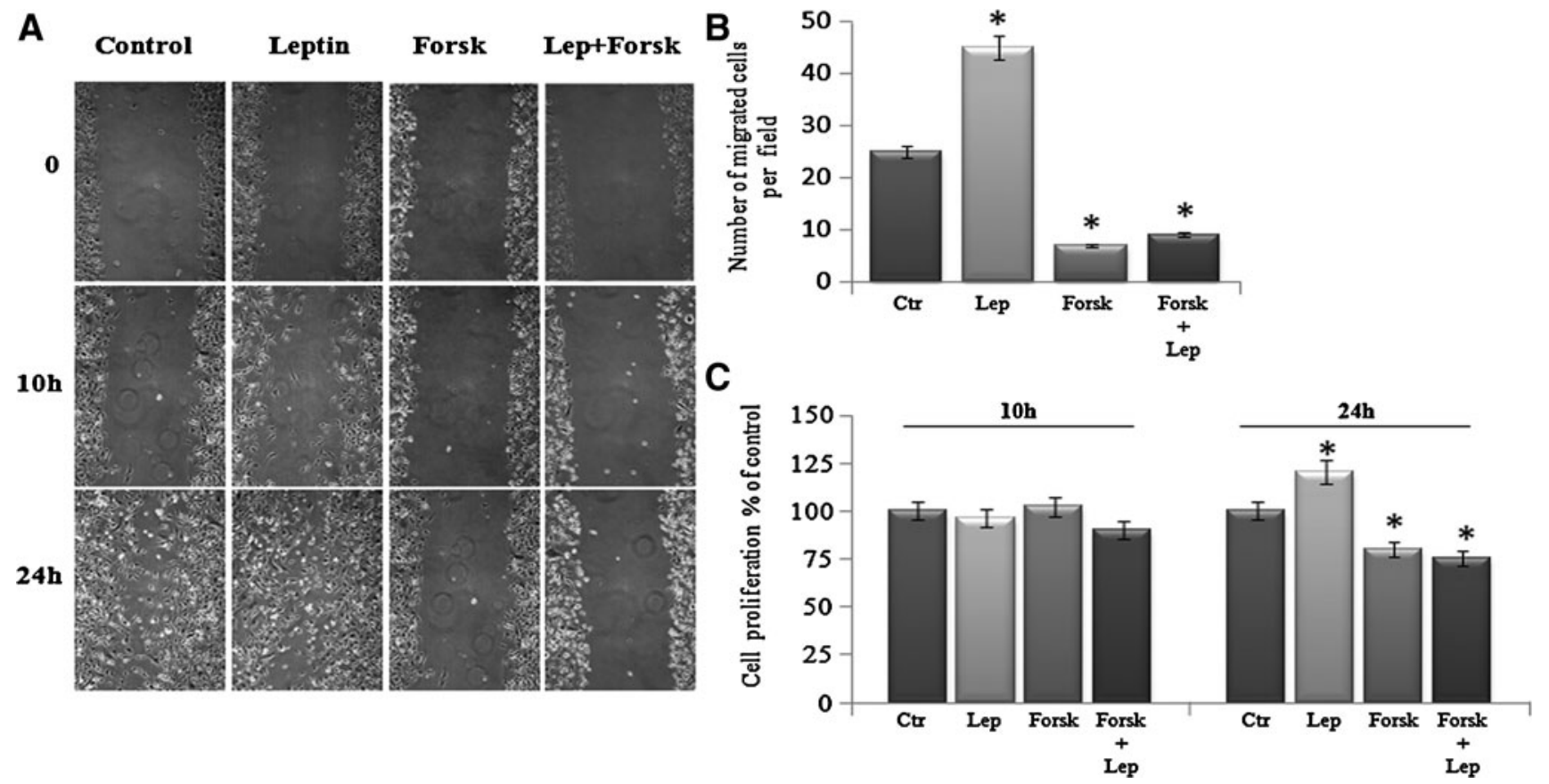

FIG. 1. Effects of leptin, forskolin, and leptin plus forskolin on MDA-MB-231 cell migration and proliferation. (A) Cell migration was determined by wound-healing assay. MDA-MB-231 cells were untreated (Ctr) or treated with $40 \mathrm{nM}$ leptin (Lep), $1 \mu \mathrm{M}$ forskolin (Forsk), or $40 \mathrm{nM}$ leptin plus $1 \mu \mathrm{M}$ forskolin (Forsk+Lep). The phase contrast images of the wounds were recorded after 0,10 , and $24 \mathrm{~h}$, at the identical location of the initial image. The images are representative of at least four different experiments with similar results. (B) The cell migration was assessed by the transwell migration assay in untreated MDA-MB-231 cells and cells treated with $40 \mathrm{nM}$ leptin, $1 \mu \mathrm{M}$ forskolin, or $40 \mathrm{nM}$ leptin plus $1 \mu \mathrm{M}$ forskolin for $24 \mathrm{~h}$. (C) MDA-MB-231 cells were untreated or treated with $40 \mathrm{nM}$ leptin, $1 \mu \mathrm{M}$ forskolin, or $40 \mathrm{nM}$ leptin plus $1 \mu \mathrm{M}$ forskolin for 10 and $24 \mathrm{~h}$ and then cell proliferation was measured by 3-[4,5-dimethylthiazol-2-yl]-2,5-diphenyltetrazolium bromide (MTT) assay. Data represent the means and SD of three independent experiments. ${ }^{*} p<0.01$ vs. control untreated cells.

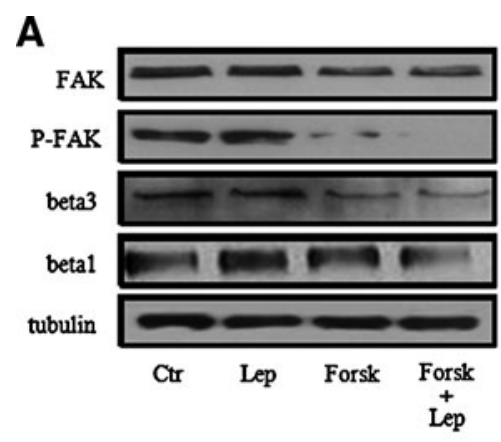

B
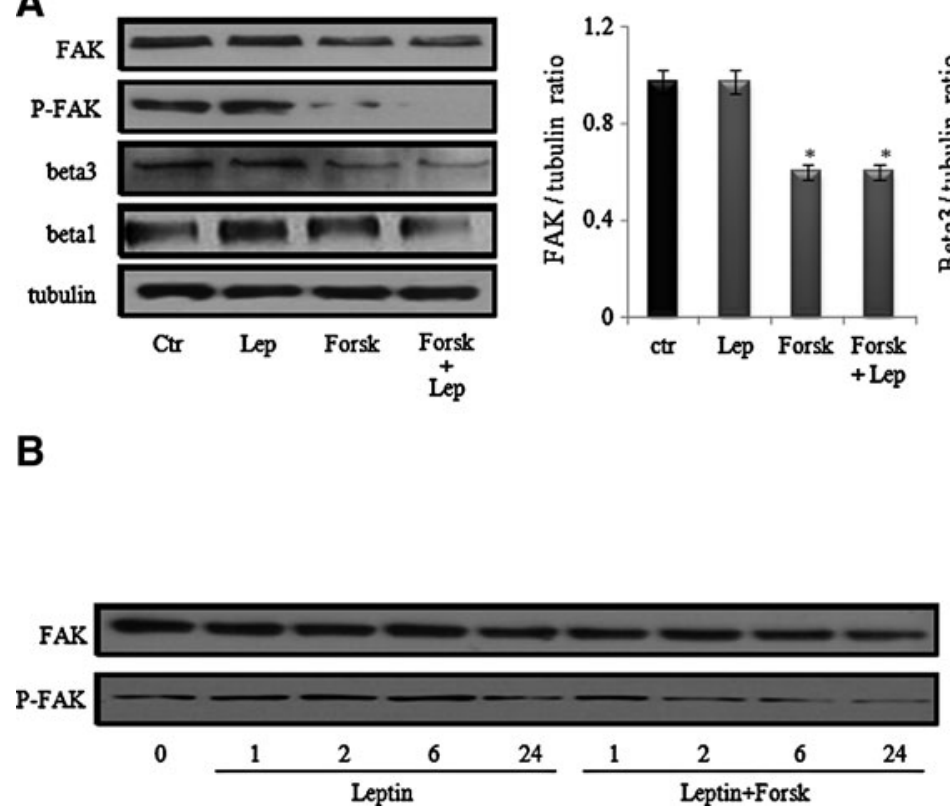
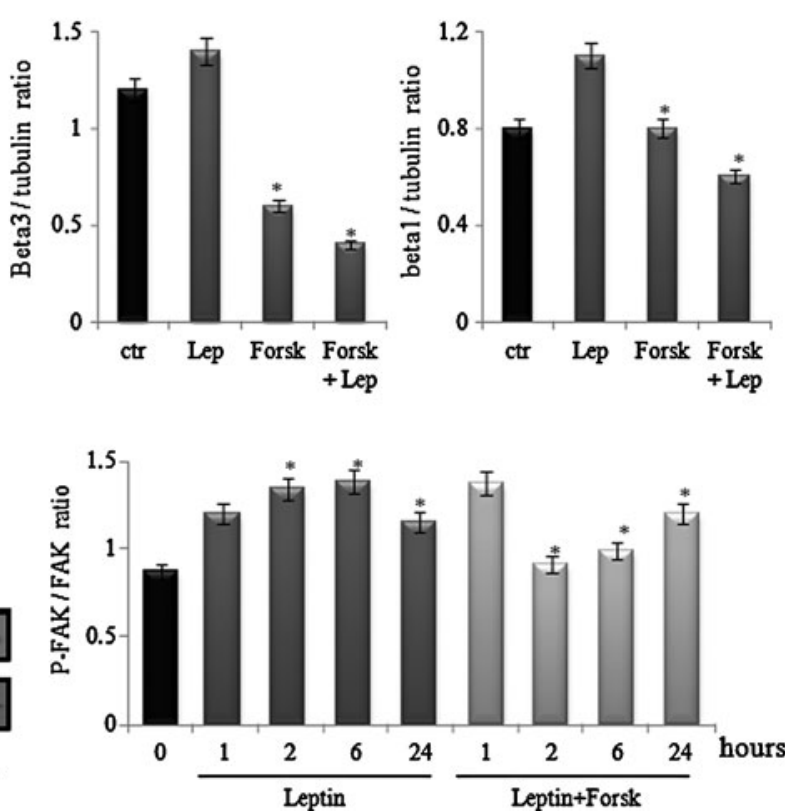

FIG. 2. Effects of leptin, forskolin, and leptin plus forskolin on some integrin subunits and focal adhesion kinase (FAK) protein and phosphorylation levels. MDA-MB-231 cells were untreated or treated with $40 \mathrm{nM}$ leptin, $1 \mu \mathrm{M}$ forskolin, or 40 $\mathrm{nM}$ leptin plus $1 \mu \mathrm{M}$ forskolin for $24 \mathrm{~h}$ (A) and during a time course from $1 \mathrm{~h}$ up to $24 \mathrm{~h}$ (B). Forty micrograms of cell extracts was subjected to SDS-PAGE and blotted with antibodies against the indicated proteins. The images are representative of three different experiments with similar results. Graphs showing the densitometric intensity of bands ratio are shown. The intensities of signals were expressed as arbitrary units. ${ }^{*} p<0.05$ vs. control untreated cells. 
forskolin treatment, even in presence of leptin (Fig. 2A). $\beta 1$ Integrin subunit protein levels also appear decreased mainly in response to leptin plus forskolin treatment. Figure 2A also shows that exposure of cells to forskolin resulted in a dramatic decrease of FAK phosphorylation level compared to control and/or leptin-treated ones, and also a clear decrease of total amount of FAK protein could be seen in response to forskolin. Notably, the inhibition of FAK phosphorylation by forskolin is already evident after $2 \mathrm{~h}$ of treatment and maintained up to $24 \mathrm{~h}$ (Fig. 2B).

\section{cAMP elevation relevantly affects PKA subunits and ERK1/2 and STAT3 protein and phosphorylation levels}

Previously, we found that exposure of MDA-MB-231 cells to leptin resulted in a strong phosphorylation of both ERK1/2 and STAT3 that was detectable at $30 \mathrm{~min}$, maintained until $4 \mathrm{~h}$, and declined to basal levels at $24 \mathrm{~h} .^{20}$

More recently, we found that exposure of MDA-MB-231 cells to leptin plus forskolin for $3 \mathrm{~h}$ resulted in a dramatic decrease of ERK1/2 and STAT3 phosphorylation compared to leptin alone. In other terms leptin lacks the ability to trigger ERK1/2 and STAT3 activation at early times in the presence of forskolin. ${ }^{21}$

Here we further investigate the forskolin/leptin-induced effects on ERK1/2 and STAT3 signaling for longer times and in experimental condition used for in vitro woundhealing cell migration assay (see Materials and Methods).
To this purpose, confluent cells were serum starved $(0.1 \%$ serum) for $24 \mathrm{~h}$, after which numerous gaps (to enrich the population of cells committed to migrate) were introduced into the monolayer cells by dragging a pipette tip across the cell surface. Medium and nonadherent cells were removed, cells were washed twice with PBS, and new $0.1 \%$ serum medium without (control) or with leptin, forskolin, or leptin plus forskolin was added; then cells were cultured for up to $24 \mathrm{~h}$.

Afterward, Western blotting was applied to examine the protein and phosphorylation levels of ERK1/2 and STAT3. As shown in Figure $3 \mathrm{~A}-\mathrm{C}$, we found that exposure of cells to forskolin inhibited the leptin-induced phosphorylation of ERK1/2 in a strong and prolonged manner for up to $24 \mathrm{~h}$, without obvious changes in total protein amount. Intriguingly, Figure 3A-C also shows that exposure of MDA-MB231 cells to forskolin resulted in an initial inhibition of phosphorylation of STAT3 in response to leptin (up to $10 \mathrm{~h}$ of treatment), and then in a decrease of STAT3 protein abundance with an increase of its phosphorylation as a late effect at $24 \mathrm{~h}$ of treatment.

cAMP-dependent PKA is known to play an important role in cell migration, including that of breast cancer cells. $^{33-36}$

Recently, we have provided evidence that the inhibition of leptin-induced proliferation upon cAMP elevation is followed by a strong lowering of protein levels of both regulatory RI $\alpha$ and catalytic subunits of PKA, and by a consistent reduction in CREB phosphorylation. ${ }^{21}$
A

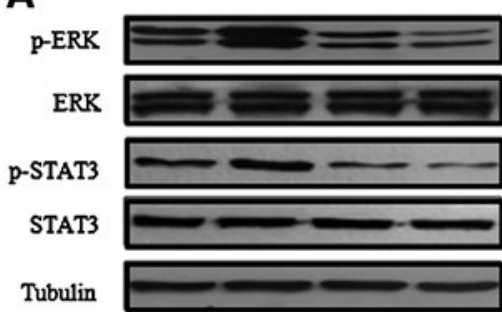

B

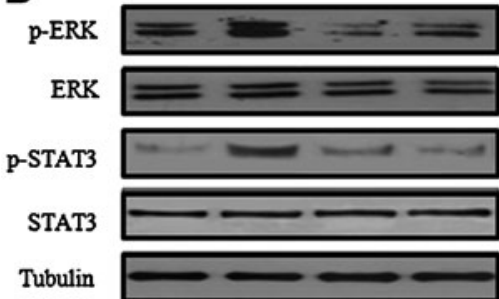

C

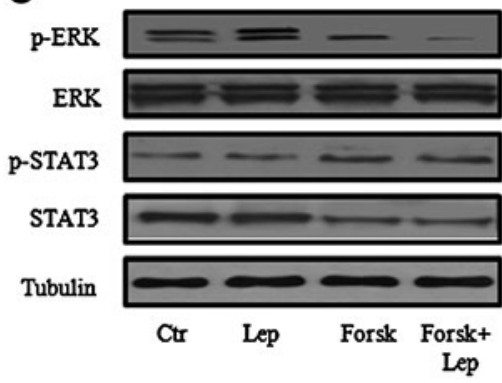

$3 \mathbf{h}$
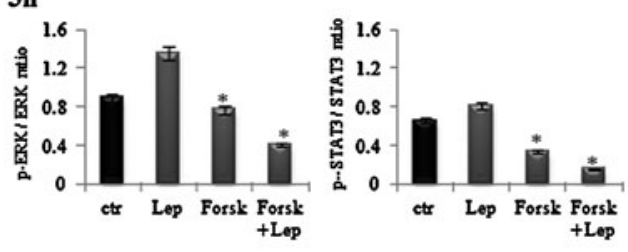

$10 \mathrm{~h}$
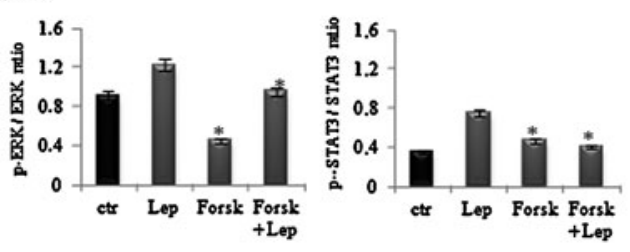

+ Lep

$24 h$
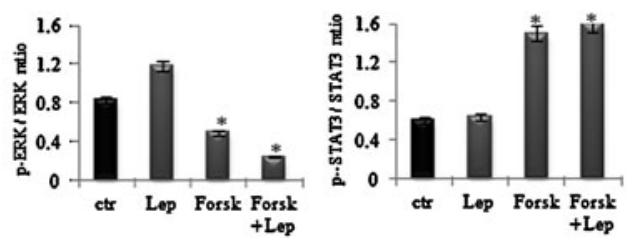

D

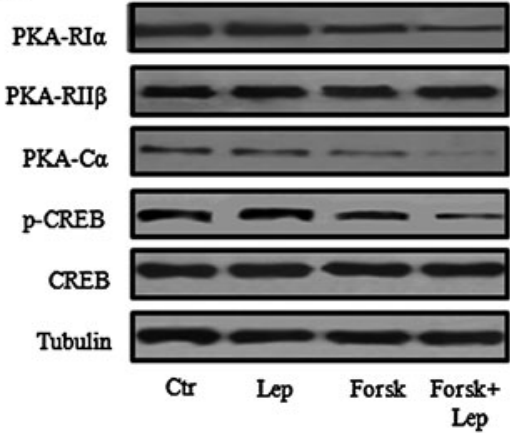

FIG. 3. Effects of leptin, forskolin, and leptin plus forskolin on ERK1/2 and STAT3 activation and on protein levels of the protein kinase A (PKA) subunits. MDA-MB-231 cells were untreated or treated with $40 \mathrm{nM}$ leptin, $1 \mu \mathrm{M}$ forskolin, or $40 \mathrm{nM}$ leptin plus $1 \mu \mathrm{M}$ forskolin for 3 (A), 10 (B), and $24 \mathrm{~h} \mathrm{(C)}$ and for $24 \mathrm{~h}$ alone (D). Forty micrograms of cell extracts was subjected to SDS-PAGE and blotted with antibodies against the indicated proteins. The image is representative of three different experiments with similar results. Graphs showing the densitometric intensity of bands ratio are shown. The intensities of signals were expressed as arbitrary units. ${ }^{*} p<0.05$ vs. control untreated cells. 
A

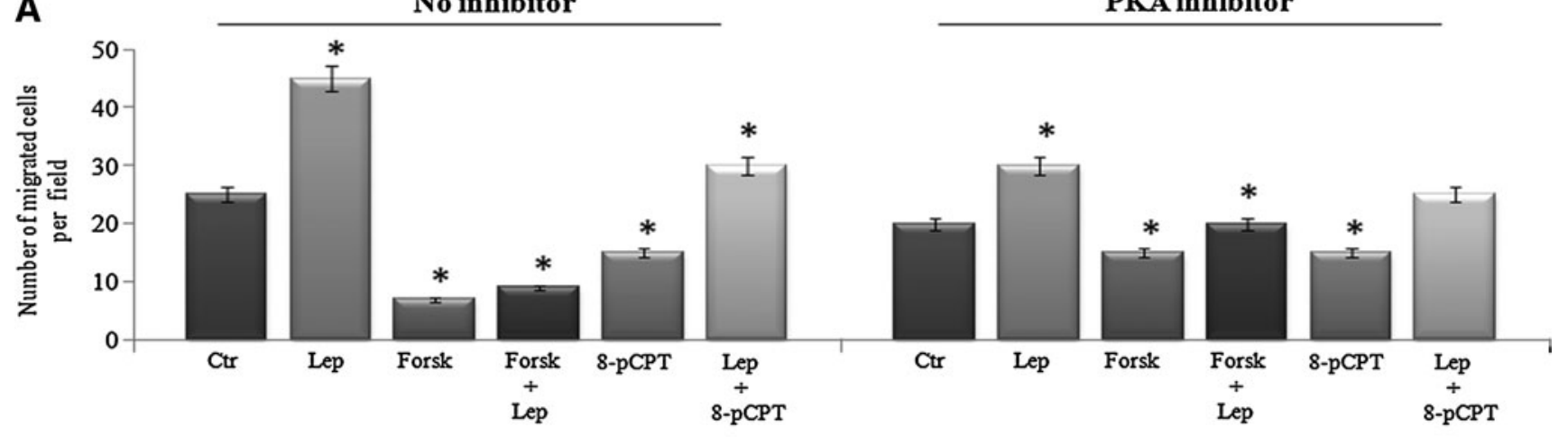

B

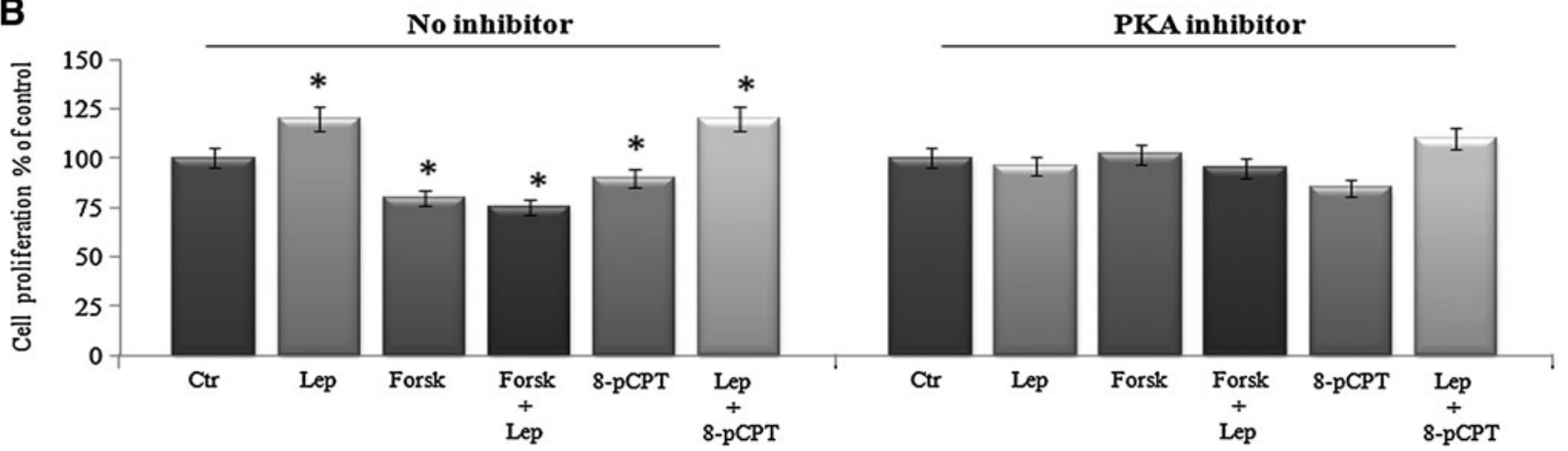

FIG. 4. Effects of PKA inhibition and Epac activation on cAMP-dependent inhibition of leptin-induced cell migration. MDAMB-231 cells were untreated or treated with $40 \mathrm{nM}$ leptin, $1 \mu \mathrm{M}$ forskolin, $50 \mu \mathrm{M}$ 8-pCPT-Me-cAMP (cAMP analogue, Epac stimulator), $40 \mathrm{nM}$ leptin plus $1 \mu \mathrm{M}$ forskolin, or $40 \mathrm{nM}$ leptin plus $50 \mu \mathrm{M}$ 8-pCPT-Me-cAMP for $24 \mathrm{~h}$ in the presence or absence of $10 \mu \mathrm{m}$ PKA inhibitor KT5720. (A) The cell migration was assessed by the transwell migration assay. (B) Cell proliferation was measured by the MTT assay. Data represent the means and SD of three independent experiments. ${ }^{*} p<0.01$ vs. control untreated cells.

To explore the possible involvement of PKA in the inhibition by cAMP elevation of leptin-induced migration, we first studied the protein levels of PKA subunits by Western blotting in cells treated or not with leptin, forskolin, or leptin plus forskolin for $24 \mathrm{~h}$ from plates managed as described earlier (see In vitro wound-healing cell migration assay). According to our previous results, Figure 3D shows that combined leptin plus forskolin treatments resulted in a strong reduction of $\mathrm{RI} \alpha$ protein levels, whereas $\mathrm{RII} \beta$ levels appeared unchanged. PKA catalytic subunits were significantly lower too, with a consistent CREB phosphorylation decrease, suggesting that PKA might have a promigratory role in MDAMB-231 cells.

\section{cAMP/PKA- and cAMP/Epac-dependent pathways are both involved in inhibition by $C A M P$ elevation of leptin-induced migration of MDA-MB-231 cells}

To further investigate the cAMP-dependent molecular mechanisms underlying the CAMP inhibition of leptin-induced migration of MDA-MB-231 cells, we used the KT5720 compound, which is a cell-permeable, selective, and potent PKA inhibitor. ${ }^{37}$ We tested its effects on migration of MDAMB-231 cells in response to leptin, forskolin, and forskolin plus leptin in both wound-healing and transwell migration assays, and we found that KT5720 antagonized, although not completely, the inhibition by forskolin of leptin-induced migration (Fig. 4A), whereas it completely prevented the antiproliferative action by cAMP elevation (Fig. 4B). Similar results were obtained by using H89 PKA inhibitor (data not shown). In addition, we included in these experiments a CAMP analogue that specifically activates Epac and not PKA. ${ }^{38,39}$ Notably, and similar to the cAMP elevating agent forskolin, the Epac activator also has an inhibitory effect, although to a different extent, on leptin-induced cell migration (Fig. 4A).

\section{Discussion}

Currently, new effective therapies are needed for the treatment of metastatic breast cancer. ${ }^{5,6,40,41}$ Importantly, given the relevant role of leptin in breast cancer growth and metastasis, the leptin system has emerged as a new and promising therapeutic target for breast cancer. ${ }^{19}$

Actually, agents able to block leptin activity, including soluble leptin receptors that bind free circulating leptin, leptin antagonists that bind to but do not activate leptin receptors, and either specific anti-leptin receptors monoclonal antibodies that bind to the receptor preventing leptin signaling or anti-leptin antibodies, are in initial stages of development. ${ }^{42}$ However, novel strategies to suppress leptin signaling and counteract its biological effects are warranted. 
Recently, we demonstrated that in MDA-MB-231 triplenegative breast cancer cells, intracellular cAMP elevation completely abrogates both ERK1/2 and STAT3 phosphorylation in response to leptin and, very surprisingly, provided evidence that when cAMP levels are increased, leptin drives cells towards apoptosis accompanied by a marked downregulation of $\mathrm{Bcl} 2$ protein levels in a PKA-dependent manner. $^{20,21}$

To the best of our knowledge, the data presented in the current study provide the first evidence indicating a neutralization of leptin-induced biological effect simply by raising intracellular cAMP levels. Interestingly, we found a positive pharmacological interaction between leptin and cAMPelevating compounds that allowed a reduction in the effective doses of cAMP-elevating drugs in vitro, thus potentially decreasing their undesirable side effects in vivo. ${ }^{23}$

The present study extends evidence of cAMP elevation as a simple way to neutralize leptin-induced biological effects in breast cancer cells. Specifically, here we report that cAMP-elevating agents relevantly inhibit some leptininduced metastatic properties of MDA-MB-231 triplenegative human breast cancer cell line, a well-established and largely used model system of highly invasive breast cancer cells. We also found that the inhibition by cAMPelevating agents of leptin-mediated cell migration is accompanied by a strong decrease of $\beta 3$ integrin subunit and FAK protein levels.

Notably, the $\beta 3$ integrin subunit is up-regulated and associated with a metastatic phenotype and increased motility in breast cancer cells, as well as in a variety of other cancer cells, such as melanoma, prostate carcinoma, and osteosarcoma. ${ }^{39,43-45}$ Integrins modulate breast cancer migration and invasion in multiple ways via a range of signaling pathways. A common integrin signaling molecule is FAK, which has been suggested to play a significant role in tumor formation and metastasis. ${ }^{31}$ Remarkably, several pathological studies report FAK protein overexpression in cancers, including breast cancer. ${ }^{46}$ Furthermore, FAK overexpression correlates with more aggressive and invasive breast carcinomas, and it was recently shown that the FAK-encoding PTK2 gene is amplified in human breast cancer, with high levels of FAK mRNA expression predicting significantly shorter metastasis-free survival. ${ }^{46-48}$

Importantly, we demonstrate that the inhibition by cAMP elevation of leptin-induced cell migration of MDA-MB-231 cells is consistently accompanied by a dramatic decrease of $\beta 3$ integrin subunit and FAK protein levels, suggesting that the metastatic potential of MDA-MB-231 cells would be strongly attenuated in response to cAMP elevation.

Initial investigation of the underlying molecular mechanisms indicated that the cAMP-induced inhibition of migration of MDA-MB-231 cells in response to leptin is dynamically accompanied by profound changes in phosphorylation status and protein levels of ERK1/2 and STAT3. The Ras/Raf/Erk signaling pathway is relevant and frequently activated in breast cancer. ${ }^{49}$ A blockade of such a signaling pathway is considered a relevant strategy for therapeutic intervention. ${ }^{50}$ Importantly, we found that treatment with cAMP-elevating agents completely abrogated ERK1/2 phosphorylation in response to leptin, resulting in a prolonged inhibition of Erk1/2 phosphorylation (without significant change in the total amount of ERK1/2 protein).
On the other hand, multiple lines of evidence place STAT3 at a central node in the development, progression, and maintenance of many human tumors, including breast cancer, and STAT3 has been validated as an anticancer target in several contexts. ${ }^{51}$ Most of the major human malignancies, including breast cancer, manifest elevated levels of constitutively activated STAT3 as well as transcriptional profiles that are consistent with STAT3-regulated gene expression. ${ }^{52}$ Recently, approaches that have been pursued to target STAT3 for developing anticancer drugs that might therapeutically inhibit the STAT3 signaling pathway have been straighforwardly reviewed. ${ }^{53}$ Importantly, we found that exposure of MDAMB-231 cells to cAMP resulted in an initial inhibition of phosphorylation of STAT3 in response to leptin (up to $10 \mathrm{~h}$ of treatment), followed by a decrease of STAT3 protein abundance with an increase of its phosphorylation as a late effect (at $24 \mathrm{~h}$ of treatment).

Our data suggest that cAMP elevation strongly inhibits migration of MDA-MB-231 cells in response to leptin, possibly through inhibition of ERK1/2 and Stat3 signaling pathways within the tumor cells themselves. The detailed molecular mechanism underlying this growth inhibition by cAMP is just starting to be investigated and interplay between these pathways (and possibly others) is very likely implicated in the observed inhibition of migration of MDAMB-231 cells.

Whatever the exact mechanism(s) here, we report that cAMP elevation acts as a potent inhibitor of some leptininduced metastatic properties of MDA-MB-231 highly aggressive breast cancer cells.

It is largely known that cAMP is involved in cell migration, including that of breast cancer cells, with an important role played mainly by cAMP-dependent PKA. ${ }^{29,33-36}$ cAMP/PKA has been reported to have positive and negative effects on migration of different cell types, very likely depending on the spatial-temporal distribution and activation of cAMP/PKA itself.

Notably, we provided evidence that treatment with cAMPelevating agents, resulting in a blocking of leptin-induced migration of MDA-MB-231 cells, strongly lowers protein levels of both regulatory RI $\alpha$ and catalytic subunits of PKA and consistently reduces CREB phosphorylation. Our data are consistent with a promigratory role of PKA in such cells. Accordingly, KT5720 and/or H89 PKA inhibitors antagonize the inhibition by cAMP elevation of leptininduced migration, although not completely, suggesting that other cAMP-dependent, but PKA-independent mechanisms are very likely involved. In agreement with this hypothesis, we found that a CAMP analogue which specifically activates Epac and not PKA has an inhibitory effect on leptin-induced cell migration as well. Further and more exhaustive studies are warranted to better investigate the role of cAMP-dependent molecular mechanisms in the inhibition by cAMP elevation of leptin-induced migration.

Collectively, here we demonstrate that a cAMP increase strongly inhibits leptin-induced migration of MDA-MB-231 cells. This phenomenon is accompanied by a strong decrease of levels of $\beta 3$ integrin subunit and FAK prometastatic proteins and is preceded by an inhibition of pro-proliferative and prometastatic ERK1/2 and STAT3 signaling pathways.

New effective therapies are needed for the treatment of metastatic breast cancer. The leptin system has emerged as a new 
and promising therapeutic target for breast cancer. The present study confirms initial evidence for the efficacy of cAMP elevation against the oncogenic effects of leptin and suggests that raising intracellular cAMP levels might inhibit breast cancer metastasis triggered by high leptin levels.

\section{Acknowledgments}

Funding was provided by contract grant sponsor PRIN 2009. This work was supported by the Italian Ministry for Research, PRIN 2009.

\section{Author Disclosure Statement}

No competing financial interests exist.

\section{References}

1. American Cancer Society. Cancer Facts and Figures 2011. Atlanta, GA: American Cancer Society; 2011.

2. Veronesi U, Boyle P, Goldhirsch A, Orecchia R, Viale G. Breast cancer. Lancet. 2005;365:1727-1741.

3. Van't Veer LJ, Weigelt B. Road map to metastasis. Nat Med. 2003;9:999-1000.

4. Polacheck WJ, Zervantonakis IK, Kamm RD. Tumor cell migration in complex microenvironments. Cell Mol Life Sci. 2012 Aug 25 [Epub ahead of print]; DOI: 10.1007/s00018012-1115-1.

5. Rakha EA, Chan S. Metastatic triple-negative breast cancer. Clin Oncol. 2011;23:587-600.

6. Pal SK, Childs BH, Pegram M. Triple negative breast cancer: unmet medical needs. Breast Cancer Res Treat. 2011;125: 627-636.

7. Zhang Y, Proenca R, Maffei M, et al. Positional cloning of the mouse obese gene and its human homologue. Nature. 1994; 372:425-432.

8. Jeong JK, Szabo G, Raso GM, et al. Deletion of prolyl carboxypeptidase attenuates the metabolic effects of dietinduced obesity. Am J Physiol Endocrinol Metab. 2012; 302:E1502-1510.

9. Schwartz MW, Baskin DG, Kaiyala KJ, Woods SC. Model for the regulation of energy balance and adiposity by the central nervous system. Am J Clin Nutr. 1999;69:584-596.

10. Garofalo C, Surmacz E. Leptin and cancer. J Cell Physiol. 2006;207:12-22.

11. Yin N, Wang D, Zhang $H$, et al. Molecular mechanisms involved in the growth stimulation of breast cancer cells by leptin. Cancer Res. 2004;64:5870-5875.

12. Ishikawa M, Kitayama J, Nagawa H. Enhanced expression of leptin and leptin receptor (OB-R) in human breast cancer. Clin Cancer Res. 2004;10:4325-4331.

13. Jardé T, Caldefie-Chezet F, Damez M, et al. Leptin and leptin receptor involvement in cancer development: a study on human primary breast carcinoma. Oncol Rep. 2008;19: 905-911.

14. Revillion F, Charlier M, Lhotellier V, et al. Messenger RNA expression of leptin and leptin receptors and their prognostic value in 322 human primary breast cancers. Clin Cancer Res. 2006;12(7 Pt 1):2088-2094.

15. Frankenberry KA, Skinner H, Somasundar $P$, et al. Leptin receptor expression and cell signaling in breast cancer. Int J Oncol. 2006;28:985-993.

16. Ray A, Nkhata KJ, Cleary MP. Effects of leptin on human breast cancer cell lines in relationship to estrogen receptor and HER2 status. Int J Oncol. 2007;30:1499-1509.
17. Knight BB, Oprea-Ilies GM, Nagalingam A, et al. Survivin upregulation, dependent on leptin-EGFR-Notch1 axis, is essential for leptin-induced migration of breast carcinoma cells. Endocr Relat Cancer. 2011;18:413-428.

18. Andò $S$, Catalano $S$. The multifactorial role of leptin in driving the breast cancer microenvironment. Nat Rev Endocrinol. 2011;8:263-275.

19. Ray A, Cleary MP. Leptin as a potential therapeutic target for breast cancer prevention and treatment. Expert Opin Ther Targets. 2010;14:443-451.

20. Naviglio S, Di Gesto D, Romano M, et al. Leptin enhances growth inhibition by cAMP elevating agents through apoptosis of MDA-MB-231 breast cancer cells. Cancer Biol Ther. 2009;8:1183-1190.

21. Naviglio S, Di Gesto D, Illiano F, et al. Leptin potentiates antiproliferative action of cAMP elevation via protein kinase A down-regulation in breast cancer cells. J Cell Physiol. 2010; 225:801-809.

22. Schwede F, Maronde E, Genieser H, Jastorff B. Cyclic nucleotide analogs as biochemical tools and prospective drugs. Pharmacol Ther. 2000;87:199-226.

23. Vitale G, Dicitore A, Mari D, Cavagnini F. A new therapeutic strategy against cancer: cAMP elevating drugs and leptin. Cancer Biol Ther. 2009;8:1190-1196.

24. Dittmer A, Vetter M, Schunke D, et al. Parathyroid hormonerelated protein regulates tumor-relevant genes in breast cancer cells. J Biol Chem. 2006;281:14563-14572.

25. Chiosi E, Spina A, Sorrentino A, et al. Change in TNF-alpha receptor expression is a relevant event in doxorubicininduced $\mathrm{H} 9 \mathrm{c} 2$ cardiomyocyte cell death. J Interferon Cytokine Res. 2007;27:589-597.

26. Naviglio S, Spina A, Chiosi E, et al. Inorganic phosphate inhibits growth of human osteosarcoma U2OS cells via adenylate cyclase/cAMP pathway. J Cell Biochem. 2006;98:1584-1596.

27. Du J, Sun C, Hu Z, et al. Lysophosphatidic acid induces MDA-MB-231 breast cancer cells migration through activation of PI3K/PAK1/ERK signaling. PLoS One. 2010;5:e15940.

28. Kim SH, Nagalingam A, Saxena NK, et al. Benzyl isothiocyanate inhibits oncogenic actions of leptin in human breast cancer cells by suppressing activation of signal transducer and activator of transcription 3. Carcinogenesis. 2010;32:359-367.

29. Chen L, Zhang JJ, Huang XY. cAMP inhibits cell migration by interfering with Rac-induced lamellipodium formation. J Biol Chem. 2008;283:13799-13805.

30. Li DM, Feng YM. Signaling mechanism of cell adhesion molecules in breast cancer metastasis: potential therapeutic targets. Breast Cancer Res Treat. 2011;128:7-21.

31. Golubovskaya VM, Cance W. Focal adhesion kinase and p53 signal transduction pathways in cancer. Front Biosci. 2010;15: 901-912.

32. Luo M, Guan JL. Focal adhesion kinase: a prominent determinant in breast cancer initiation, progression and metastasis. Cancer Lett. 2010;289:127-139.

33. Chioni AM, Shao D, Grose R, Djamgoz MB. Protein kinase A and regulation of neonatal Nav1.5 expression in human breast cancer cells: activity-dependent positive feedback and cellular migration. Int J Biochem Cell Biol. 2010;42:346-358.

34. Hansen C, Howlin J, Tengholm A, et al. Wnt-5a-induced phosphorylation of DARPP-32 inhibits breast cancer cell migration in a CREB-dependent manner. J Biol Chem. 2009;284:27533-27543.

35. McKenzie AJ, Campbell SL, Howe AK. Protein kinase A activity and anchoring are required for ovarian cancer cell migration and invasion. PLoS One. 2011;6:e26552. 
36. Fan CF, Mao XY, Wang EH. Elevated p-CREB-2 (ser 245) expression is potentially associated with carcinogenesis and development of breast carcinoma. Mol Med Rep. 2012;5: 357-362.

37. Davies SP, Reddy H, Caivano M, Cohen P. Specificity and mechanism of action of some commonly used protein kinase inhibitors. Biochem J. 2000;351(Pt 1):95-105.

38. Enserink JM, Christensen AE, de Rooij J, et al. A novel Epacspecific CAMP analogue demonstrates independent regulation of Rap1 and ERK. Nat Cell Biol. 2002;4:901-906.

39. Naviglio S, Di Gesto D, Borrelli V, et al. Novel molecular mechanisms by inorganic phosphate in osteosarcoma U2OS cells. Front Biosci. 2011;E3:1249-1258.

40. Alvarez RH, Valero V, Hortobagyi GN. Emerging targeted therapies for breast cancer. J Clin Oncol. 2010;28:3366-3379.

41. Reddy KB. Triple-negative breast cancers: an updated review on treatment options. Curr Oncol. 2011;18:173-179.

42. Otvos L Jr, Surmacz E. Targeting the leptin receptor: a potential new mode of treatment for breast cancer. Exp Rev Anticancer Ther. 2011;11:1147-1150.

43. Baum O, Hlushchuk R, Forster A, et al. Increased invasive potential and up-regulation of MMP-2 in MDA-MB-231 breast cancer cells expressing the beta3 integrin subunit. Int J Oncol. 2007;30:325-332.

44. Liu H, Radisky DC, Yang D, et al. MYC suppresses cancer metastasis by direct transcriptional silencing of $\alpha \mathrm{v}$ and $\beta 3$ integrin subunits. Nat Cell Biol. 2012;14:567-574.

45. Nasulewicz-Goldeman A, Uszczyńska B, Szczaurska-Nowak $\mathrm{K}$, Wietrzyk J. siRNA-mediated silencing of integrin $\beta 3$ expression inhibits the metastatic potential of B16 melanoma cells. Oncol Rep. 2012;28:1567-1573.

46. Golubovskaya VM, Conway-Dorsey K, Edmiston SN, et al. FAK overexpression and p53 mutations are highly correlated in human breast cancer. Int J Cancer. 2009;125:1735-1738.
47. Theocharis SE, Klijanienko JT, Padoy E, et al. Focal adhesion kinase (FAK) immunocytochemical expression in breast ductal invasive carcinoma (DIC): correlation with clinicopathological parameters and tumor proliferative capacity. Med Sci Monit. 2009;15:BR221-BR226.

48. Agochiya M, Brunton VG, Owens DW, et al. Increased dosage and amplification of the focal adhesion kinase gene in human cancer cells. Oncogene. 1999;18:5646-5653.

49. Santen RJ, Song RX, McPherson R, et al. The role of mitogenactivated protein (MAP) kinase in breast cancer. J Steroid Biochem Mol Biol. 2002;80:239-256.

50. Santarpia L, Lippman SM, El-Naggar AK. Targeting the MAPK-RAS-RAF signaling pathway in cancer therapy. Expert Opin Ther Targets. 2012;16:103-119.

51. Jing N, Tweardy DJ. Targeting Stat3 in cancer therapy. Anticancer Drugs. 2005;16:601-607.

52. Germain D, Frank DA. Targeting the cytoplasmic and nuclear functions of signal transducers and activators of transcription 3 for cancer therapy. Clin Cancer Res. 2007; 13:5665-5669.

53. Johnston PA, Grandis JR. STAT3 signaling: anticancer strategies and challenges. Mol Interv. 2011;11:18-26.

Address correspondence to: Silvio Naviglio, $\mathrm{MD}, \mathrm{PhD}$ Department of Biochemistry and Biophysics Second University of Naples Medical School

Via L. De Crecchio 7 80138 Naples Italy

E-mail: silvio.naviglio@unina2.it 